\title{
Increased Plasma Levels of Tumor Necrosis Factor- $\alpha$ in Asymptomatic/“Indeterminate" and Chagas Disease Cardiomyopathy Patients
}

\author{
Renata Cristina Ferreira, Barbara M lanni*, Lucia CJ Abel, Paula Buck*, Charles Mady*, \\ Jorge Kalil**, Edecio Cunha-Neto**/+
}

Laboratório de Imunologia *Divisão de Cardiopatias Gerais, Instituto do Coração **Divisião de Imunologia Clínica e Alergia, Departamento de Clínica Médica, Faculdade de Medicina, Universidade de São Paulo, Av. Dr. Eneas de Carvalho Aguiar, 44, Bloco II, $9^{\circ}$ andar, 05403-000 São Paulo, SP, Brasil

We compared plasma tumor necrosis factor- $\alpha(T N F-\alpha)$ levels among asymptomatic/ "indeterminate" Chagas disease patients (ASY) and patients across the clinical spectrum of chronic Chagas disease cardiomyopathy (CCC). Idiopathic dilated cardiomyopathy (DCM) patients and normal controls (NC) were included as controls. ASY Chagas disease patients had significantly higher plasma TNF- $\alpha$ levels than NC. TNF- $\alpha$ levels among severe CCC patients with significant left ventricular ( $L V)$ dysfunction were similar to those of DCM patients, showing average 2-fold higher levels than CCC patients without LV dysfunction and ASY patients, and 8-fold higher levels than NC. In Chagas disease, chronic TNF- $\alpha$ production prior to heart failure may play a role in CCC progression.

Key words: Chagas disease cardiomyopathy - tumor necrosis factor-alpha - Trypanosoma cruzi

Up to $30 \%$ of the $18-20$ million individuals in Latin America infected with the intracellular protozoan parasite Trypanosoma cruzi develop an inflammatory cardiomyopathy (chronic Chagas disease cardiomyopathy, CCC), 15-30 years after initial infection. A fraction of those will develop dilated cardiomyopathy with significant left ventricular (LV) dysfunction. Survival after presentation of heart failure in CCC is at least 2-fold shorter than that observed in idiopathic dilated cardiomyopathy (DCM) (Mady et al. 1994, Bestetti \& Muccillo 1997). A diffuse myocarditis with extensive fibrosis and very scarce $T$. cruzi parasites (Higuchi et al. 1993) are the hallmark of CCC heart lesions (Mady et al. 1999). The mononuclear infiltrate produces significant amounts of proinflammatory and T1-type cytokines like tumor necrosis factor- $\alpha$ (TNF$\alpha)$ and Interferon- $\gamma($ IFN- $\gamma$ ) (Reis et al. 1993, 1997, Abel et al. 2001). Parasites are seldom found in the heart lesions of CCC (Higuchi et al. 1993), and autoimmune T cells crossreactively recognizing cardiac myosin and $T$. cruzi proteins were isolated from CCC heart tissue (Cunha-Neto et al. 1996). The majority of infected individuals, however, remain asymptomatic, in the so-called "indeterminate" form of the disease $(65-70 \%)$ or develop its digestive form $(5 \%)$. The intense immigration from endemic areas has posed transfusion-related infection with $T$. cruzi as a potential threat in the United States (Kirchhoff 1989, Shulman et al. 1997).

Supported by grants from Fapesp, CNPq and the Howard Hughes Medical Institute.

${ }^{+}$Corresponding author. Fax: +55-11-3082.9350. E-mail: edecunha@usp.br

Receved 18 September 2002

Accepted 23 January 2003
Increased circulating levels of TNF- $\alpha$ were observed in heart failure patients from diverse aetiologies (Levine et al. 1990, Ferrari et al. 1995, Torre-Amione et al. 1996). It is likely that the predominant mechanism of upregulation of TNF- $\alpha$ production is secondary to advanced heart failure itself, such as low cardiac output and intestinal bacterial translocation (Muller-Werdan et al. 1998). Evidence for a direct heart damaging role of TNF- $\alpha$ (Feldman et al. $2000)$ supports the notion that increased TNF- $\alpha$ production may play a significant role in the pathogenesis of advanced heart failure.

T. cruzi membrane lipids with bacterial endotoxin-like effects induce the production of significant amounts of TNF- $\alpha$ and the other proinflammatory cytokines: interleukin (IL)-1, IL-6, and IL-12 (Almeida et al. 2000). Chronic Chagas disease patients, asymptomatic/“indeterminate" chronic Chagas disease patients (ASY) or CCC with and without left ventricular dysfunction bear a lowgrade, lifelong T. cruzi infection (Britto et al. 1995), and display increased production of IL-12 induced IFN- $\gamma$ (Ribeirão et al. 2000, Abel et al. 2001) which in turn can upregulate TNF- $\alpha$ production (Tarleton 1988, Abrahamsohn \& Coffman 1996). Given the increased parasite-induced stimulus for proinflammatory cytokine production and the expected stimulus derived from heart failure in severe Chagas disease cardiomyopathy patients, the aim of this study was study plasma TNF- $\alpha$ levels across the clinical spectrum of Chagas disease cardiomyopathy. For that matter, we studied plasma TNF- $\alpha$ levels among different clinical forms of chronic Chagas disease, idiopathic dilated cardiomyopathy (DCM) patients and normal controls (NC).

\section{MATERIALS AND METHODS}

Patients and sample preparation - All patients were subjected to anti-T. cruzi serological blood tests employing at least two distinct methodologies, electrocardio- 
graphy and uni and bidimensional echocardiography. Exclusion criteria included major systemic or associated cardiological disease or organ transplantation. Chagas disease patients (diagnosed with at least two positive anti- $T$. cruzi serological blood tests employing distinct methodologies) were divided in three groups: asymptomatic "indeterminate" T. cruzi seropositive individuals (ASY) with a normal electrocardiogram (ECG) and bidimensional echocardiography $(n=27)$, CCC with significant LV dysfunction (left ventricular ejection fraction (LVEF) $\leq 50 \%$ measured by echocardiography; $\mathrm{n}=27$ ), $\mathrm{CCC}$ without significant LV dysfunction (ECG alterations-bundle blocks and hemiblocks, LVEF $>50 \% ; n=52)$. DCM patients $(\mathrm{n}=$ 16) were subjected coronariography to exclude ischemic heart disease. Patients were followed at the Heart Institute (InCor), University of São Paulo Medical School. Heart failure patients received standard therapy with angiotensin conversion enzyme inhibitors, loop diuretics and beta-blockers; none were receiving amiodarone or milrinone at the time of sample collection. Ethylenediaminetetraacetate, sodium salt (EDTA)-anticoagulated peripheral blood was collected from the antecubital vein from all studied subjects, centrifuged at $4^{\circ} \mathrm{C}$ and the plasma was frozen at $-80^{\circ} \mathrm{C}$. Samples were also collected from $T$. cruzi seronegative, normal volunteers as a control group (NC; $n=24)$. Subjects gave their informed consent and sample collection procedures have been cleared by the Internal Review Board of the Heart Institute and University of São Paulo Medical School.

Quantification of plasma TNF- $\alpha$ - TNF- $\alpha$ levels in plasma samples were measured with the high sensitivity Quantikine HS, Human TNF- $\alpha$ kit (R\&D systems). Briefly, $200 \mu \mathrm{l}$ of each sample was added in duplicate wells to the supplied 96-well plate sensitized with anti-TNF- $\alpha$ antibody, and the assay developed according to manufacturer's directions. Quantitation limit was $0.5 \mathrm{pg} / \mathrm{ml}$.

Statistical analysis - The non-parametric KruskalWallis test was used to compare TNF- $\alpha$ levels among clinical groups. Fisher's exact test was used to compare proportions of subjects presenting high TNF- $\alpha$ levels among clinical groups. Spearman's Correlation was used to test for correlation between two variables.

\section{RESULTS}

Baseline characteristics of subjects in each clinical group are shown in the Table. The male/female ratio is dichotomous, with a significant concentration of male subjects among CCC patients with lower LVEF values or DCM, as compared to the female predominance among CCC patients with higher LVEF values or the ASY group. Plasma TNF- $\alpha$ levels were significantly higher among Chagas disease patients than among $\mathrm{NC}(P<0.001$; Fig. 1). While $94 \%$ of plasma samples from Chagas disease patients had TNF- $\alpha$ values above $1 \mathrm{pg} / \mathrm{ml}$, only $12 \%$ of control plasma samples had similar levels, a highly discriminatory situation for Chagas disease $(P<0.0001)$.

We observed that plasma samples with high TNF- $\alpha$ values (above $4 \mathrm{pg} / \mathrm{ml}$ ) were basically only observed among CCC and DCM patients with LVEF $\leq 50 \%$ (33\% and $50 \%$, respectively) rather than among CCC with LVEF $>50 \%$, ASY, and NC $(8 \%, 11 \%$ and 0 , respectively; $P<$ 0.01 , DCM or CCC LVEF $\leq 50 \%$ vs other groups; Fig. 2). Furthermore, TNF- $\alpha$ levels among CCC patients with LVEF $\leq 50 \%$ were similar to those of DCM patients, significantly higher than the ASY or CCC patients with LVEF $>50 \%(P$ $<0.05)$ and 8-fold higher than NC $(P<0.001)$ (Fig. 2). Plasma TNF- $\alpha$ levels were similar among ASY patients and CCC patients with $\mathrm{LVEF}>50 \%$; their average plasma TNF- $\alpha$ levels were 4-fold higher than that of NC $(P<0.001)$. In spite of the lower average age of the NC group as compared to the other groups, we found no correlation between age and plasma TNF- $\alpha$ levels among NC or Chagas disease/DCM patients (Spearman's correlation), suggesting that the age difference did not contribute to the increased patient TNF- $\alpha$ levels. We found no significant difference in plasma TNF- $\alpha$ between males and females. However, we observed a statistically significant negative correlation between plasma TNF- $\alpha$ and LVEF in CCC patients $(P=0,0268, \mathrm{r}=-0,2492$; Spearman's correation; data not shown).

\section{DISCUSSION}

We have shown that CCC patients with LVEF $\leq 50 \%$ display plasma TNF- $\alpha$ values comparable to those of low LVEF DCM patients. Together with the observation that

TABLE

Average plasma tumor necrosis factor- $\alpha(\mathrm{TNF}-\alpha)$ levels and demographics from clinical groups

\begin{tabular}{lllllll}
\hline & $\begin{array}{l}\text { Normal } \\
\text { controls }\end{array}$ & $\begin{array}{l}\text { Chagas } \\
\text { disease }\end{array}$ & ASY & $\begin{array}{l}\text { CCC } \\
\text { LVEF }>50 \%\end{array}$ & $\begin{array}{l}\text { CCC } \\
\text { LVEF } \leq 50 \%\end{array}$ & DCM \\
\hline Number & 24 & 106 & 27 & 52 & 27 & 16 \\
$\begin{array}{l}\text { Mean age } \pm \text { SD } \\
\text { (range) }\end{array}$ & $32.8 \pm 8.2$ & $54.1 \pm 10.5$ & $54 \pm 10.9$ & $53 \pm 10.4$ & $54.2 \pm 14.1$ & $50.1 \pm 18.7$ \\
Male/female ratio & $(21-47)$ & $(22-76)$ & $(41-74)$ & $(31-76)$ & $(22-75)$ & $(21-87)$ \\
LVEF \pm SD & 1.4 & 1.3 & 0.5 & 0.76 & 1.7 & 4.33 \\
$($ range) & $\geq 65 \%$ & $64 \pm 13 \%$ & $\geq 65 \%$ & $65 \pm 8 \%$ & $33 \pm 5 \%$ & $36 \pm 5 \%$ \\
TNF- $\alpha \pm$ SD $(\mathrm{pg} / \mathrm{ml})$ & $0.56 \pm 0.36$ & $2.97 \pm 2.82$ & $2.46 \pm 1.56$ & $2.39 \pm 1.36$ & $4.61 \pm 4.77$ & $3.97 \pm 3.15$ \\
\hline
\end{tabular}

ASY: asymptomatic/“indeterminate” Chagas disease patients; CCC: chronic Chagas disease cardiomyopathy; DCM: idiopathic dilated cardiomyopathy; LVEF: left ventral ejection fraction 


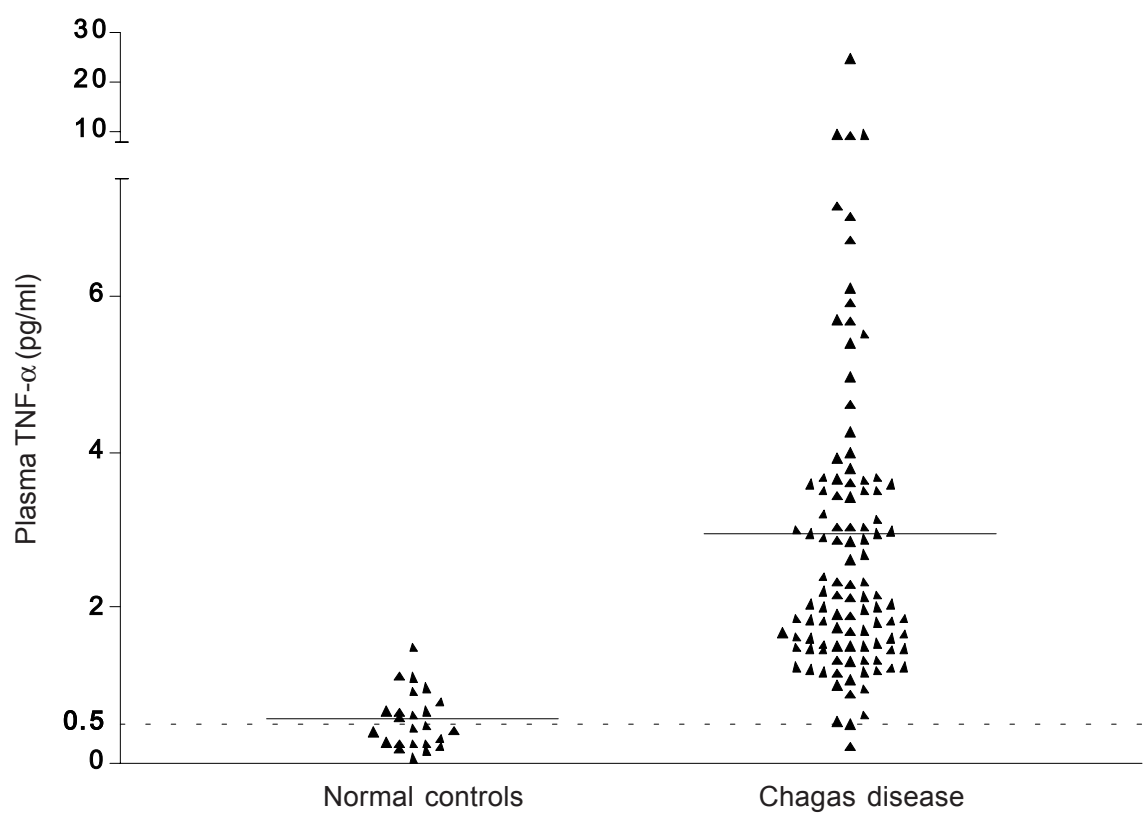

Fig. 1: plasma tumor necrosis factor- $\alpha($ TNF- $\alpha)$ levels among Chagas disease patients $(n=106)$ and normal controls $(n=24)$. EDTAplasma samples were collected and stored at $-80^{\circ} \mathrm{C}$. TNF- $\alpha$ levels were measured with a high sensitivity TNF- $\alpha$ "sandwich" immunoassay kit. Horizontal lines indicate the average values. Each data point represents the TNF- $\alpha$ level of a single plasma sample. Chagas disease vs controls, $P<0.001$.

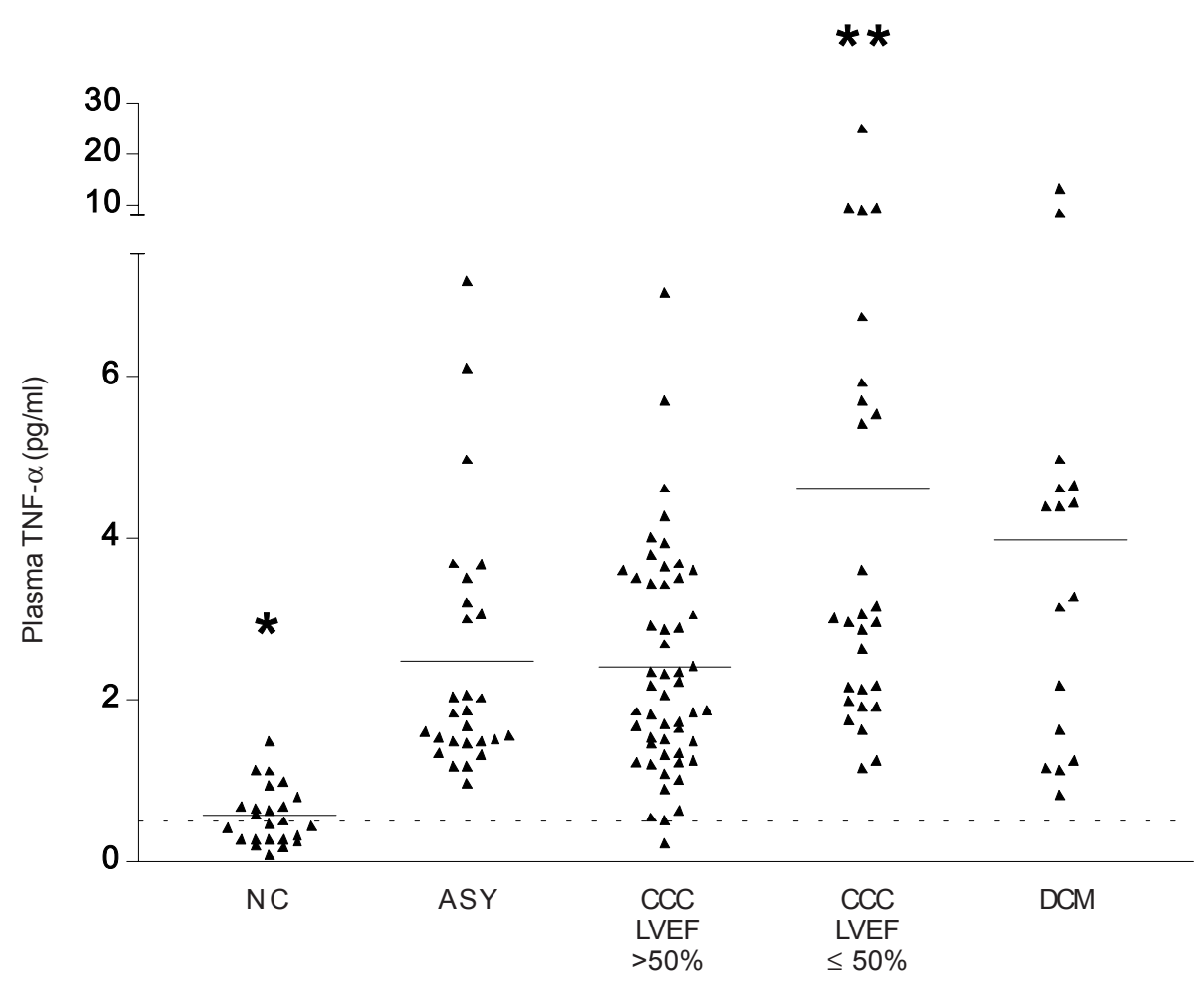

Fig. 2: plasma tumor necrosis factor- $\alpha$ (TNF- $\alpha$ ) levels among different clinical forms of Chagas disease, idiopathic dilated cardiomyopathy (DCM) patients and normal controls $(\mathrm{NC})$. NC individuals $(\mathrm{n}=24)$, asymptomatic/"indeterminate" chronic Chagas disease patients (ASY; $\mathrm{n}=27)$, and CCC with left ventricular ejection fraction (LVEF) $>50 \%(\mathrm{n}=52)$ Chagas disease cardiomyopathy patients with LVEF $\leq 50 \%$ $(\mathrm{n}=27)$, and DCM patients $(\mathrm{n}=16)$. EDTA-plasma samples were collected and stored at $-80^{\circ} \mathrm{C}$. TNF- $\alpha$ levels were measured with a high sensitivity TNF- $\alpha$ "sandwich" immunoassay kit. Horizontal lines indicate the average values. Each data point represents the TNF- $\alpha$ level of a single plasma sample. CCC (LVEF $\leq 50 \%)$ vs DCM, $P>0.05$; CCC (LVEF $\leq 50 \%)$ vs CCC (LVEF $>50 \%), P<0.01 ;$ CCC (LVEF $\leq 50 \%)$ vs ASY, $P<0.01 ; \mathrm{NC}$ vs all other groups, $P<0.001$. 
plasma TNF- $\alpha$ bears an inverse correlation with LVEF among CCC patients, these data suggest that, among low LVEF CCC patients, the predominant mechanism of upregulation of TNF- $\alpha$ production is secondary to advanced heart failure itself, such as low cardiac output and intestinal bacterial translocation (Muller-Werdan et al. 1998). However, the finding that high TNF- $\alpha$ values (above $4 \mathrm{pg} / \mathrm{ml}$ ) already occur in individuals displaying LVEF as high as $50 \%$ suggests that $50 \%$ LVEF may be a functional threshold for increased TNF- $\alpha$ production independent from advanced heart failure. Furthermore, we observed that even ASY Chagas disease patients display increased levels of plasma TNF- $\alpha$ as compared to control samples, in line with the increased production of other inflammatory cytokines such as IFN- $\gamma$ in CCC (Abel et al. 2001). Taking into account that all Chagas disease patients bear chronic infection by T. cruzi, the increase in plasma TNF$\alpha$ values shown by ASY patients or CCC with LVEF $>50 \%$ can probably be attributed to T. cruzi-induced monocyte production of the cytokine as described (Almeida et al. 2000). Our results contradict a recent report that did not find detectable levels of TNF- $\alpha$ in serum samples of 91 Chagas disease patients (Ward et al. 1999). This is most likely due to the high detection limit of the TNF- $\alpha$ detection kit used by the authors of the previous study $(10 \mathrm{pg} /$ $\mathrm{ml}$ ) compared to the $0.5 \mathrm{pg} / \mathrm{ml}$ quantification level in the present study. Out of the 106 samples from Chagas disease patients in our study, only 4 showed values higher than $10 \mathrm{pg} / \mathrm{ml}$. Furthermore, standard serum collection procedures allow long incubation times, often at $37^{\circ} \mathrm{C}$, for clot formation prior to serum separation and freezing, which can lead to proteolytic loss of low-concentration substances such as circulating cytokines.

There is accumulating evidence for a direct heart damaging role of TNF- $\alpha$ including a negative inotropic effect, ventricular remodeling and induction of dilated cardiomyopathy in animals and human subjects (Feldman et al. 2000), as well as the positive results in therapeutic trials with TNF- $\alpha$ synthesis inhibitors and blockers (Sliwa et al. 1998, Bozkurt et al. 2001). It is thus possible that the observed increase in TNF- $\alpha$ production before the onset of congestive heart failure in Chagas disease may play a role in the worse prognosis of Chagas cardiomyopathy (Mady et al. 1994, Bestetti \& Muccillo 1997), as compared to other cardiomyopathies, where the increase in plasma TNF- $\alpha$ is usually found only in advanced heart failure (Kubota et al. 2000). Recent results from our group have shown that severe CCC patients carrying TNF- $\alpha$ genetic polymorphisms associated to high TNF- $\alpha$ production display a significantly shorter survival than similar patients bearing other alleles (Drigo $\mathrm{S}$ et al. unpublished data), further reinforcing the pathogenetic role of TNF- $\alpha$ in the progression of CCC. Finally, results suggest that therapy with TNF- $\alpha$ synthesis inhibitors and blockers may be at least as beneficial in chronic Chagas disease cardiomyopathy as in other aetiologies of heart failure. Experimental studies on the safety of TNF- $\alpha$ blocking therapy in animal models chronically infected with $T$. cruzi may authorize clinical trials to evaluate its impact on disease progression and mortality.

\section{REFERENCES:}

Abel LC, Rizzo LV, Ianni B, Albuquerque F, Bacal F, Carrara D, Bocchi EA, Teixeira HC, Mady C, Kalil J, Cunha-Neto E 2001. Chronic Chagas disease cardiomyopathy patients display an increased IFN-gamma response to Trypanosoma cruzi infection. J Autoimmun 17: 99-107.

Abrahamsohn IA, Coffman RL 1996. Trypanosoma cruzi: IL10, TNF, IFN-gamma, and IL-12 regulate innate and acquired immunity to infection. Exp Parasitol 84: 231-244.

Almeida IC, Camargo MM, Procopio DO, Silva LS, Mehlert A, Travassos LR, Gazzinelli RT, Ferguson MA 2000. Highly purified glycosylphosphatidylinositols from Trypanosoma cruzi are potent proinflammatory agents. EMBO J 19: 14761485.

Bestetti RB, Muccillo G 1997. Clinical course of Chagas heart disease: a comparison with dilated cardiomyopathy. Int $J$ Cardiol 60: 187-193.

Bozkurt B, Torre-Amione G, Warren MS, Whitmore J, Soran OZ, Feldman AM, Mann DL 2001. Results of targeted anti-tumor necrosis factor therapy with Etanercept (ENBREL) in patients with advanced heart failure. Circulation 103: 1044-1047.

Britto C, Cardoso MA, Vanni CM, Hasslocher-Moreno A, Xavier SS, Oelemann W, Santoro A, Pirmez C, Morel CM, Wincker P 1995. Polymerase chain reaction detection of Trypanosoma cruzi in human blood samples as a tool for diagnosis and treatment evaluation. Parasitology 110: 241-247.

Cunha-Neto E, Coelho V, Guilherme L, Fiorelli A, Stolf N, Kalil J 1996. Autoimmunity in Chagas disease. Identification of cardiac myosin-B13 Trypanosoma cruzi protein crossreactive $\mathrm{T}$ cell clones in heart lesions of a chronic Chagas cardiomyopathy patient. J Clin Invest 98: 1709-1712.

Feldman AM, Combes A, Wagner D, Kadakomi T, Kubota T, Li YY, McTiernan C 2000. The role of tumor necrosis factor in the pathophysiology of heart failure. $\mathrm{J} \mathrm{Am} \mathrm{Coll}$ Cardiol 35: 537-544.

Ferrari R, Bachetti T, Confortini R, Opasich C, Febo O, Corti A, Cassani G, Visioli O 1995. Tumor necrosis factor soluble receptors in patients with various degrees of congestive heart failure [see comments]. Circulation 92: 1479-1486.

Higuchi ML, De Brito T, Reis MM, Bellotti G, Pereira-Barretto AC, Pileggi F 1993. Correlation between T. cruzi parasitism and myocardial inflammatory infiltrate in human chronic chagasic myocarditis: light microscopy and immunohistochemical findings. Cardio Pathol 2: 101-105.

Kirchhoff LV 1989. Is Trypanosoma cruzi a new threat to our blood supply? Ann Intern Med 111: 773-775.

Kubota T, Miyagishima M, Alvarez RJ, Kormos R, Rosenblum WD, Demetris AJ, Semigran MJ, Dec GW, Holubkov R, McTiernan CF, Mann DL, Feldman AM, McNamara DM 2000. Expression of proinflammatory cytokines in the failing human heart: comparison of recent-onset and endstage congestive heart failure. J Heart Lung Transplant 19: 819-824.

Levine B, Kalman J, Mayer L, Fillit HM, Packer M 1990. Elevated circulating levels of tumor necrosis factor in severe chronic heart failure. $N$ Engl J Med 323: 236-241.

Mady C, Cardoso RH, Barretto AC, da LP, Bellotti G, Pileggi F 1994. Survival and predictors of survival in patients with congestive heart failure due to Chagas cardiomyopathy [see comments]. Circulation 90: 3098-3102.

Mady C, Ianni BM, Arteaga E, Montes GS, Caldini EG, Andrade G, Giorgi MC, Saldiva PH 1999. Relation between interstitial myocardial collagen and the degree of clinical impairment in Chagas disease [published erratum appears in $A m J$ 
Cardiol 84:1456]. Am J Cardiol 84: 354-356, A9.

Muller-Werdan U, Engelmann H, Werdan K 1998. Cardiodepression by tumor necrosis factor-alpha. Eur Cytokine Netw 9: 689-691.

Reis DD, Jones EM, Tostes SJ, Lopes ER, Gazzinelli G, Colley DG, McCurley TL 1993. Characterization of inflammatory infiltrates in chronic chagasic myocardial lesions: presence of tumor necrosis factor-alpha+ cells and dominance of granzyme A+, CD8+ lymphocytes. Am J Trop Med Hyg 48: 637-644.

Reis MM, Higuchi Mde L, Benvenuti LA, Aiello VD, Gutierrez PS, Bellotti G, Pileggi F 1997. An in situ quantitative immunohistochemical study of cytokines and IL-2R+ in chronic human chagasic myocarditis: correlation with the presence of myocardial Trypanosoma cruzi antigens. Clin Immunol Immunopathol 83: 165-72.

Ribeirão M, Pereira-Chioccola VL, Renia L, Augusto Fragata Filho A, Schenkman S, Rodrigues MM 2000. Chagasic patients develop a type 1 immune response to Trypanosoma cruzi trans-sialidase. Parasite Immunol 22: 49-53.

Shulman IA, Appleman MD, Saxena S, Hiti AL, Kirchhoff LV 1997. Specific antibodies to Trypanosoma cruzi among blood donors in Los Angeles, California. Transfusion 37: 727 731.

Sliwa K, Skudicky D, Candy G, Wisenbaugh T, Sareli P 1998. Randomised investigation of effects of pentoxifylline on left- ventricular performance in idiopathic dilated cardiomyopathy. Lancet 351: 1091-1093.

Tarleton RL 1988. Tumour necrosis factor (cachectin) production during experimental Chagas disease. Clin Exp Immunol 73:186-90.

Torre-Amione G, Kapadia S, Lee J, Durand JB, Bies RD, Young JB, Mann DL 1996. Tumor necrosis factor-alpha and tumor necrosis factor receptors in the failing human heart. Circulation 93: 704-711.

Ward LS, Guariento ME, Fernandes GA, Maciel RMB 1999. Serum cytokines in chronic Chagas disease. Rev Soc Bras Med Trop 32: 285-289. 
412 Plasma TNF- $\alpha$ in Chagas Disease Cardiopathy - Renata Cristina Ferreira et al. 